\title{
E2F1 downregulation by arsenic trioxide in lung adenocarcinoma
}

\author{
SZE-KWAN LAM, YUAN-YUAN LI, CHUN-YAN ZHENG, LEANNE LEE LEUNG and JAMES CHUNG-MAN HO
}

Division of Respiratory Medicine, Department of Medicine, The University of Hong Kong,

Queen Mary Hospital, Hong Kong, SAR, P.R. China

Received May 7, 2014; Accepted July 1, 2014

DOI: $10.3892 /$ ijo.2014.2609

\begin{abstract}
Lung cancer is one of the most common cancers worldwide. Arsenic trioxide (ATO) has been approved by the US Food and Drug Administration for the treatment of acute promyelocytic leukemia. Nonetheless preliminary data have suggested potential activity of ATO in solid tumors including lung cancer. This study aimed to examine the underlying mechanisms of ATO in the treatment of lung adenocarcinoma. Using a panel of 7 lung adenocarcinoma cell lines, the effects of ATO treatment on cell viability, expression of E2F1 and its downstream targets, phosphatidylserine externalization, mitochondrial membrane depolarization and alteration of apoptotic/anti-apoptotic factors were studied. Tumor growth inhibition in vivo was investigated using a nude mouse xenograft model. ATO decreased cell viability with clinically achievable concentrations $(8 \mu \mathrm{M})$ in all cell lines investigated. This was accompanied by reduced expression of E2F1, cyclin A2, skp2, c-myc, thymidine kinase and ribonucleotide reductase $\mathrm{M} 1$, while $\mathrm{p}-\mathrm{c}-\mathrm{Jun}$ was upregulated. Cell viability was significantly decreased with E2F1 knockdown. Treatment with ATO resulted in phosphatidylserine externalization in $\mathrm{H} 23$ cells and mitochondrial membrane depolarization in all cell lines, associated with truncation of Bid, downregulation of Bcl-2, upregulation of Bax and Bak, caspase-9 and -3 activation and PARP cleavage. Using the $\mathrm{H} 358$ xenograft model, the tumor growth was suppressed in the ATO treatment group during 8 days of treatment, associated with downregulation of E2F1 and upregulation of truncated Bid and cleaved caspase-3. In conclusion, ATO has potent in vitro and in vivo activity in lung adenocarcinoma, partially mediated through E2F1 downregulation and apoptosis.
\end{abstract}

\section{Introduction}

Based on the updated GLOBOCAN project of the World Health Organization in 2012, breast, prostate and lung remain

Correspondence to: Dr James C.-M. Ho, Department of Medicine, The University of Hong Kong, Queen Mary Hospital, Pokfulam, Hong Kong, SAR, P.R. China

E-mail: jhocm@hku.hk

Key words: lung adenocarcinoma, arsenic trioxide, E2F1, apoptosis, xenograft the three most common global cancers (http://globocan.iarc. $\mathrm{fr} /$ ). The incidence and mortality rates of lung cancer have increased from 12.7 to $16.7 \%$ and 18.2 to $23.2 \%$ of all cancers respectively since 2008 . Lung cancer is histologically classified as non-small cell (NSCLC) or small cell carcinoma (SCLC), and is associated with distinct treatment implications. The majority (85\%) of lung cancer cases are NSCLC, comprised mostly of adenocarcinoma. Notably, tobacco smoking, preexisting lung disease, diet, occupational exposure, exposure to estrogen, and genetic predisposition are the major causes of lung cancer (1).

Systemic chemotherapy remains the cornerstone treatment for advanced or metastatic NSCLC. First-line platinum doublets with newer agents (docetaxel, gemcitabine, paclitaxel, pemetrexed or vinorelbine) and salvage monotherapy with docetaxel or pemetrexed have conferred only a modest survival benefit with 5 -year overall survival $<5 \%(2,3)$. Emerging molecularly-targeted therapy against epidermal growth factor receptor or anaplastic lymphoma kinase has provided a superior treatment option to systemic chemotherapy in patients with NSCLC driven by actionable targets. Nonetheless development of acquired drug resistance $\sim 1$ year following targeted therapy is almost inevitable (4). Thus novel effective treatment for NSCLC is urgently needed.

Arsenic trioxide (ATO), which is now a standard treatment for acute promyelocytic leukemia, has demonstrated promising activity in solid tumors including lung cancer (5-8). Nonetheless the exact mechanisms of action of ATO in NSCLC have not been fully elucidated. We have recently reported the role of ATO-induced suppression of thymidylate synthase (TYMS) in 4 lung adenocarcinoma cell lines with basal expression (9), while ATO might have other effects in cell lines not expressing TYMS. The role of E2F1 is still not fully elucidated, therefore, a panel of 7 lung adenocarcinoma cell lines with basal E2F1 expression was studied. E2F1 is a transcription factor that controls cell fate including apoptosis (10) and DNA synthesis (11). Depending on specific cancer types, the E2F1 gene can serve as an oncogene (12) with a prognostic role (13) or a tumor suppressor gene (14). This study aimed to investigate the action of ATO in lung adenocarcinoma, with an emphasis on E2F1-mediated pathways and apoptosis.

\section{Materials and methods}

Cell lines and reagents. A panel of 7 lung adenocarcinoma cell lines was obtained from the American Type Culture Collection 
(Manassas, VA, USA). Cells were incubated in RPMI-1640 culture medium $\left(\right.$ Gibco $^{\circledR}$, Life Technologies, Carlsbad, CA, USA) containing $10 \%$ fetal bovine serum (FBS) (Gibco) in a humidified atmosphere at $37^{\circ} \mathrm{C}$ with $5 \% \mathrm{CO}_{2}$. ATO was purchased from Sigma-Aldrich (St. Louis, MO, USA).

Assay of cell viability. Cell viability following ATO treatment was measured using a 3-(4,5-dimethylthiazol-2-yl)-2,5-diphenyltetrazolium bromide (MTT) assay as previously described (9).

Western blot analysis of cell lysates. Sodium dodecyl sulfatepolyacrylamide gel electrophoresis (SDS-PAGE) and western blot analysis were carried out as described (15). Primary antibodies were purchased from Cell Signaling Technology (Danvers, MA, USA). $\beta$-actin (Sigma-Aldrich) was used as a house-keeping protein.

E2F1 siRNA knockdown. Cells were cultured for $6 \mathrm{~h}$ with a mixture of transfection reagent and control (sc-37007) or E2F1 (sc-29297) siRNA (Santa Cruz Biotechnology, Inc., Santa Cruz, CA, USA) in RPMI-1640 medium. The transfected cells were maintained in $1 \%$ FBS-containing medium for 2 days. Cell viability and E2F1 expression were assessed by MTT assay and western blot analysis, respectively (9).

Phycoerythrin (PE)-conjugated Annexin V and 7-(aminoactinomycin D) AAD staining. Phosphatidylserine externalization (PS) (loss of membrane asymmetry) was examined using the PE-conjugated Annexin V and 7-AAD staining method as previously described (15).

Measurement of mitochondrial membrane potential by JC-1 staining. The fluorescent dye JC-1 was employed for the determination of mitochondrial transmembrane potential. ATO-treated cells were harvested and re-suspended for $15 \mathrm{~min}$ at $37^{\circ} \mathrm{C}$ in darkness with RPMI medium containing $2.5 \mu \mathrm{g} /$ $\mathrm{ml} \mathrm{JC}-1$ (Sigma-Aldrich). Flow analysis was performed and signals were detected by FL-1 (525 nm) and FL-2 $(575 \mathrm{~nm})$ channels (Beckman FC500).

Tumor growth inhibition in vivo. Tumor xenograft was established by subcutaneous injection of 10 million H358 cells in PBS into the back of nude mice (female, 4-week-old, 10-12 g, BALB/cAnN-nu, Charles River Laboratories, Wilmington, MA, USA). Tumors were allowed to grow for 5 days before mice were randomised to two groups. ATO at $5 \mathrm{mg} / \mathrm{kg}(\mathrm{n}=8)$ or PBS as control $(n=7)$, was daily administered intraperitoneally. Tumor growth was measured using standard calipers and body weight of mice was recorded on alternate days. Tumor volume $(\mathrm{V})$ was calculated $[\mathrm{V}=$ (length $\mathrm{x}$ width $\mathrm{x}$ width)/2] (16). Mice were sacrificed following completion of ATO treatment. Tumor xenografts were collected and homogenized to obtain protein lysates for western blot analysis. The in vivo study was approved by the Committee on the Use of Live Animals in Teaching and Research (CULATR) of the University of Hong Kong (CULATR reference no. 2510-11).

Statistical analysis. Data from three individual experiments are shown as mean \pm standard deviation (SD). Comparison between groups was performed using Student's two-tailed t-test by Prism (GraphPad Software, La Jolla, CA, USA). A p-value $<0.05$ was considered statistically significant.

\section{Results}

In vitro activity of ATO in lung adenocarcinoma. Incubation with ATO for $48 \mathrm{~h}$ reduced cell viability in different lung adenocarcinoma cell lines, with $\mathrm{IC}_{50}$ values ranging from 1.8 to $16.5 \mu \mathrm{M}(\mathrm{H} 23, \mathrm{H} 358, \mathrm{HCC} 827, \mathrm{H} 1650, \mathrm{H} 1975, \mathrm{HCC} 2935$ and HCC4006 cells: 1.8, 16.1, 2.0, 3.8, 2.6, 12.1 and $9.0 \mu \mathrm{M}$, respectively). After $72 \mathrm{~h}$ of ATO treatment, $\mathrm{IC}_{50}$ values were further decreased (H23, H358, HCC827, H1650, H1975, HCC2935 and HCC4006 cells: 0.5, 7.4, 0.08, 4.0, 1.5, 5.7 and $4.0 \mu \mathrm{M}$, respectively).

Downregulation of E2F1 and alteration of related downstream proteins. ATO reduced expression of E2F1 (Fig. 1A) in a dosedependent manner, thus downstream targets of $\mathrm{E} 2 \mathrm{~F} 1$ were also investigated. Expression of cyclin A2 (Fig. 1B) was consistently downregulated by ATO in all cell lines. ATO also decreased the expression of skp2 (all cell lines except HCC4006 cells) (Fig. 1C), c-myc (H23 and H1975 cells) (Fig. 1D), thymidine kinase (TK) (H358, H1650, HCC2935 and HCC4006 cells) (Fig. 1E) and ribonucleotide reductase M1 (RRM1) (all cell lines except HCC827 and H1975 cells) (Fig. 1F). Nevertheless ATO upregulated p-c-Jun in H23, H358, HCC827 and H1975 cells (Fig. 1G). Representative western blots are shown in Fig. 1.

E2F1 downregulation reduced cell viability. The role of E2F1 in lung adenocarcinoma was studied using siRNA knockdown. With E2F1 protein expression decreased by 50-80\% compared with control siRNA treatment, cell viability was significantly decreased by $60-88 \%$ (Fig. 2).

Phosphatidylserine (PS) externalization and mitochondrial membrane depolarization induced by ATO. ATO caused PS externalization in $\mathrm{H} 23$ cells only (Fig. 3A). Nonetheless ATO aggravated mitochondrial membrane depolarization in all cell lines in a dose-dependent manner (Fig. 3B).

Alteration of apoptosis-related factors by ATO. Truncated BID was detected in H358, H1650 and HCC2935 cells (Fig. 4A) following treatment with ATO. In contrast, there was a dosedependent downregulation of Bcl-2 in all cell lines (Fig. 4B), and upregulation of Bax in $\mathrm{H} 23$ cells (Fig. 4C). There was also a dose-dependent increase in expression of Bak in all cell lines (Fig. 4D). Expression of cleaved caspase-9 was elevated in H827 cells (Fig. 4E). On the other hand, cleaved caspase-3 (CC3) was activated in H23, HCC827, H1975 and HCC 4006 cells, but unaltered in $\mathrm{H} 1650$ and downregulated in HCC2935 cells. The expression of CC3 in H358 cells was first elevated when exposed to $5 \mu \mathrm{M}$ ATO, then suppressed with $10 \mu \mathrm{M}$ ATO (Fig. 4F). Caspase-3 expression was decreased in H358 and H2935 cells upon treatment with ATO (Fig. 4G). The expression of cleaved PARP was also augmented in $\mathrm{H} 23$, H358 and H1975 cells (Fig. 4H). Representative western blots are shown in Fig. 4.

In vivo effect of ATO on tumor xenografts. Tumor growth was observed by day 5 following implantation of H358 cells. Mice 

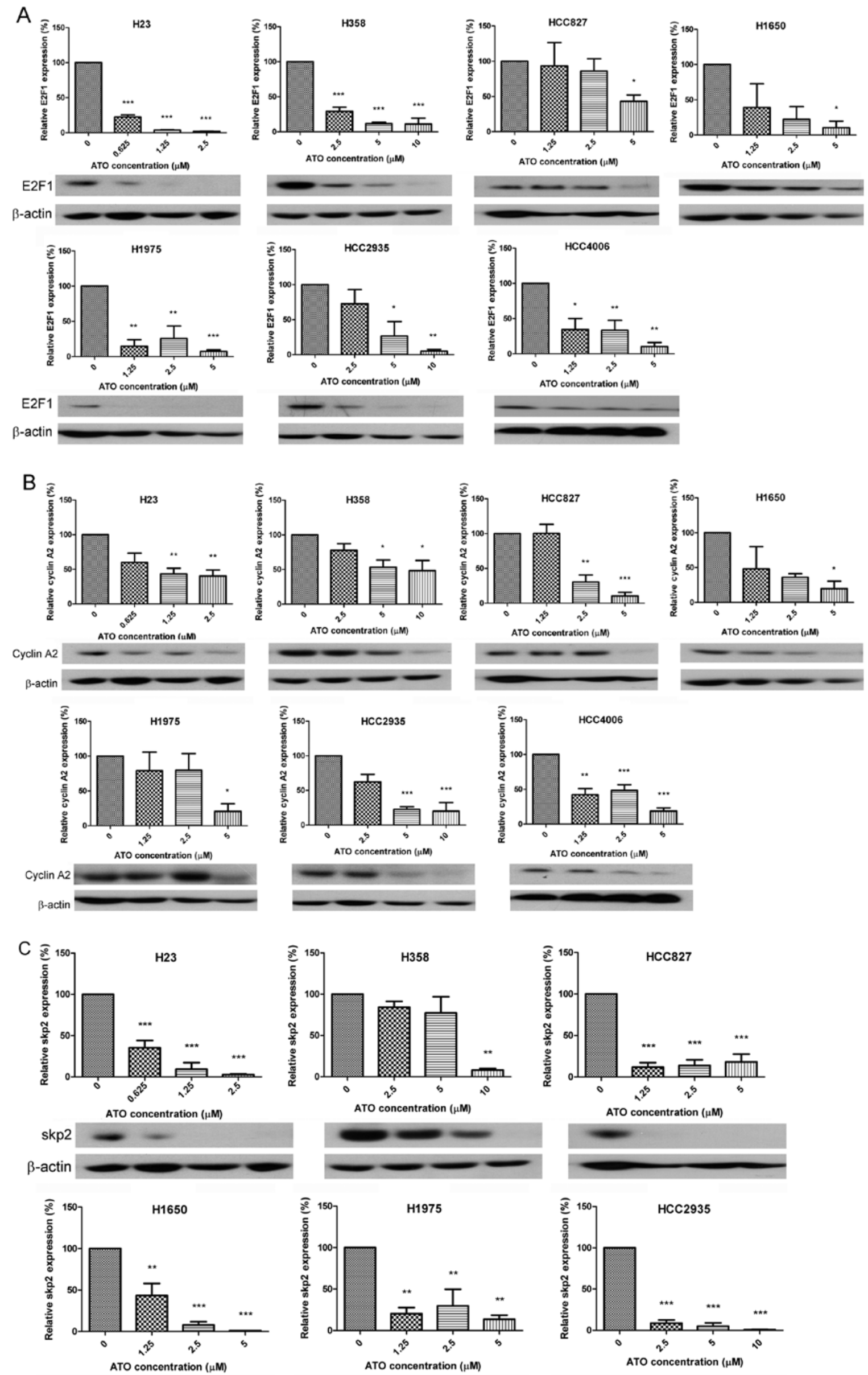

skp2
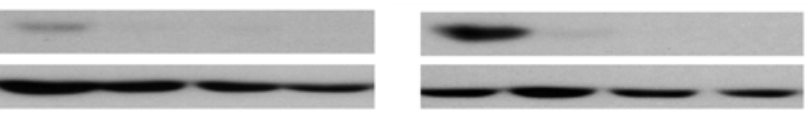

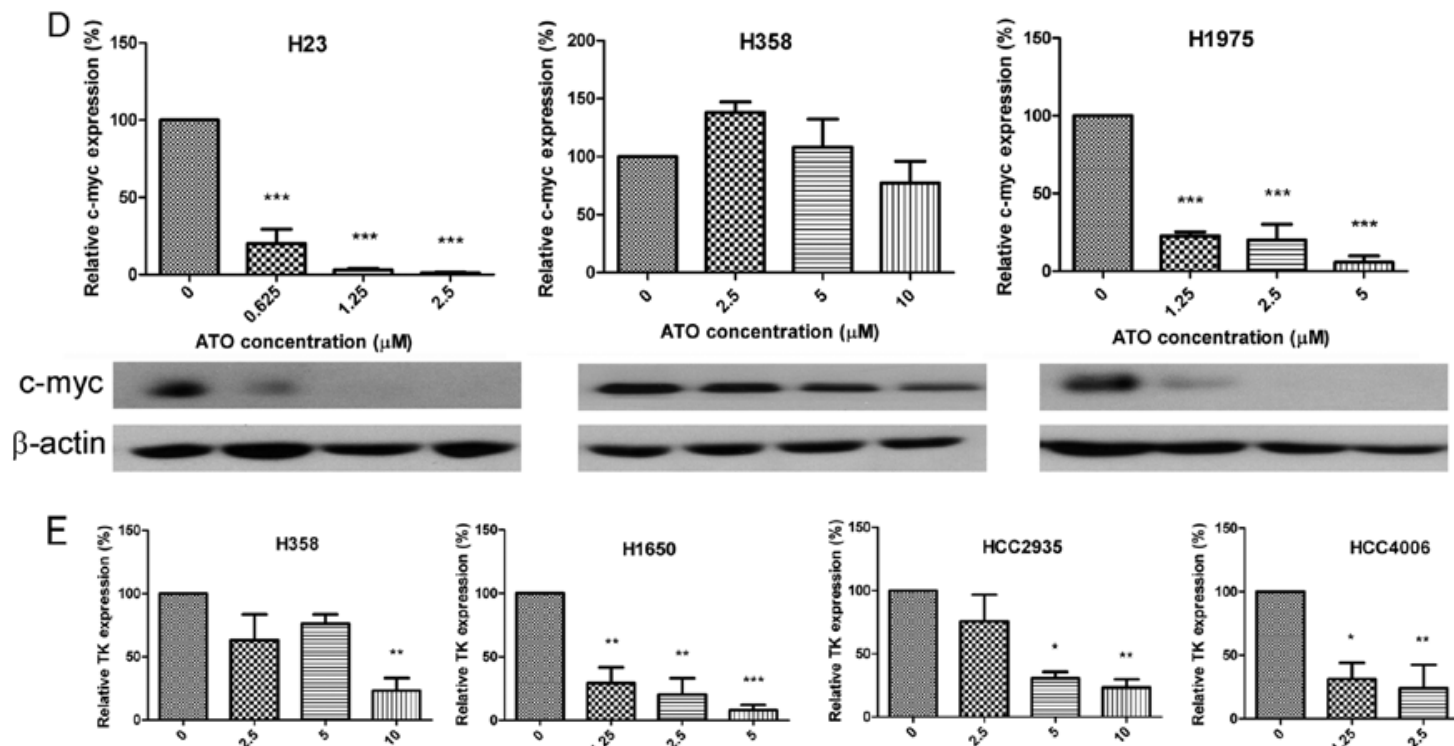

ATO concentration $(\mu \mathrm{M})$
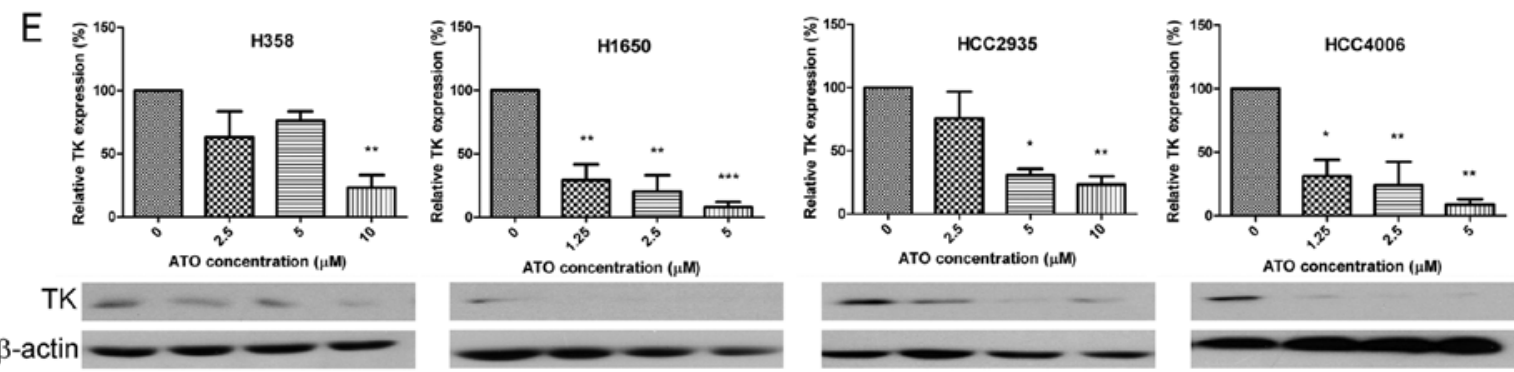

ATO concentration $(\mu M)$
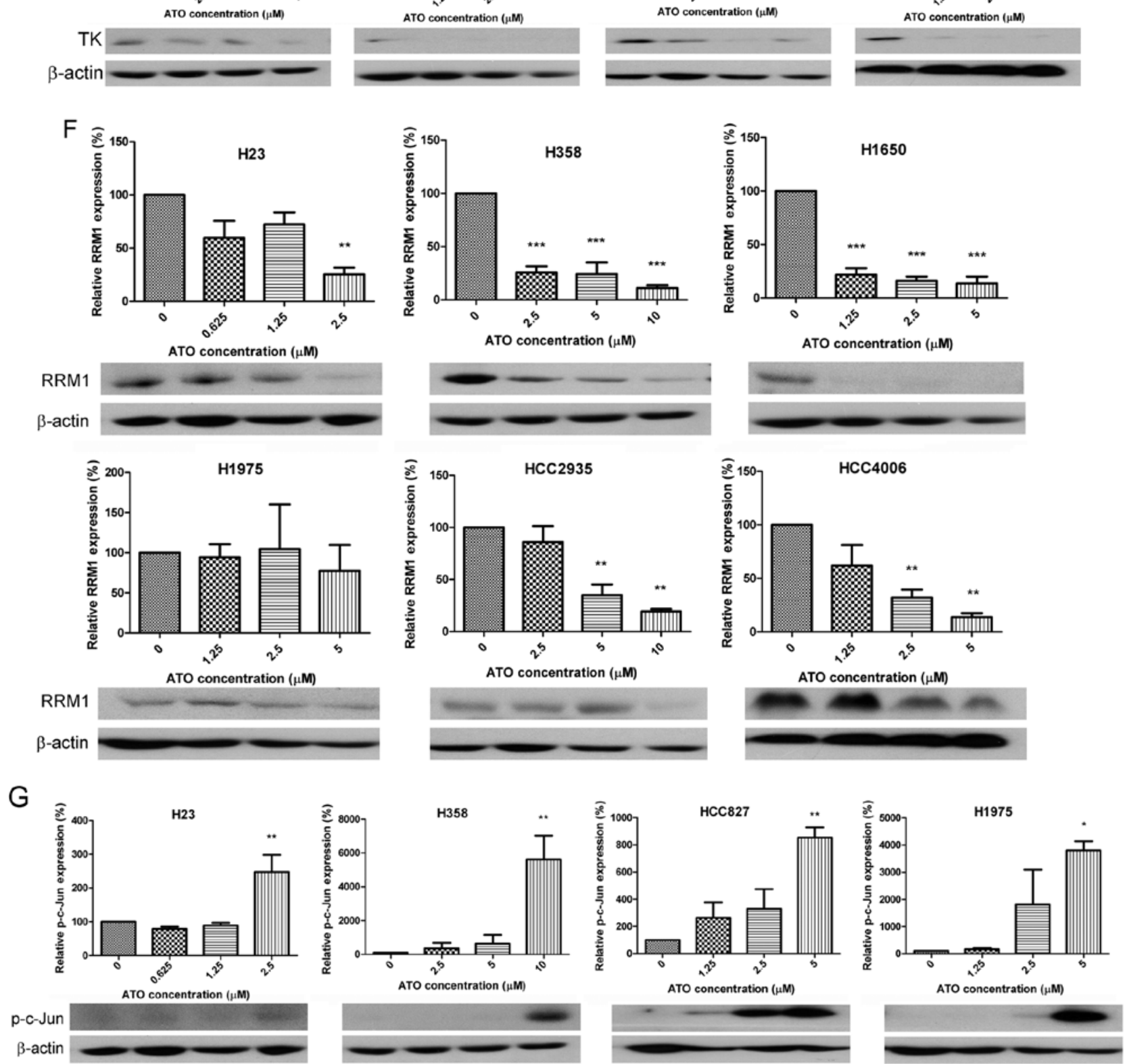

Figure 1. Downregulation of E2F1 and its downstream targets by ATO in different lung adenocarcinoma cell lines. ATO reduced expression of E2F1 (A), cyclin A2 (B), skp2 (C), c-myc (D), TK (E) and RRM1 (F), while expression of p-c-Jun (G) was increased. $\beta$-actin was used as an internal control. A representative western blot is shown for each, except for those with undetectable basal expression. Statistical significance $\left({ }^{*} \mathrm{p}<0.05,{ }^{* *} \mathrm{p}<0.01,{ }^{* * *} \mathrm{p}<0.001\right)$ is indicated for comparison with control. 


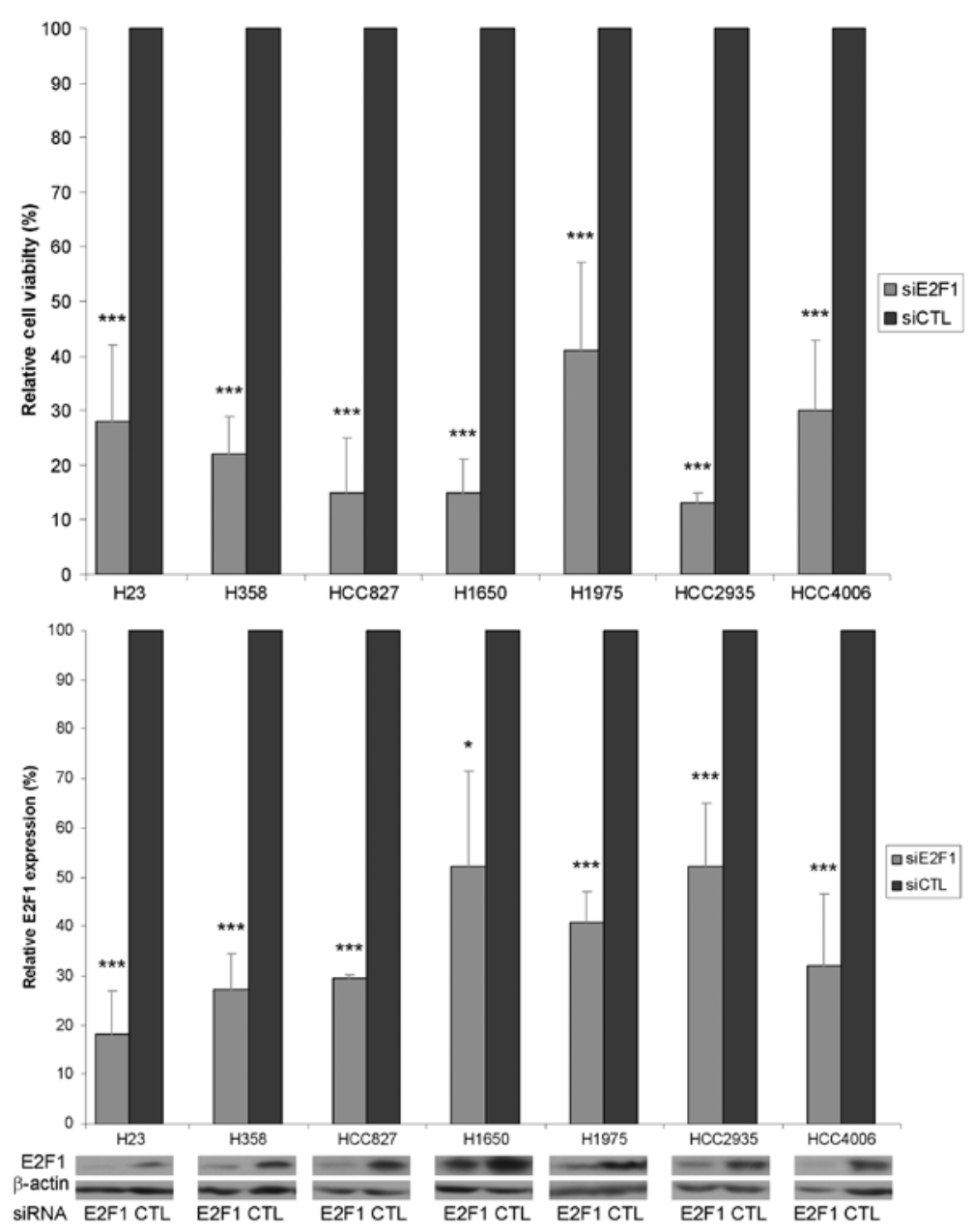

Figure 2. Effect of E2F1 knockdown on cell viability in cells treated with E2F1-targeted siRNA. With E2F1 knockdown, cell viability was significantly decreased in different cell lines. Statistical significance $\left({ }^{*} \mathrm{p}<0.05,{ }^{* *} \mathrm{p}<0.01,{ }^{* * * *} \mathrm{p}<0.001\right)$ is indicated for comparison with control.
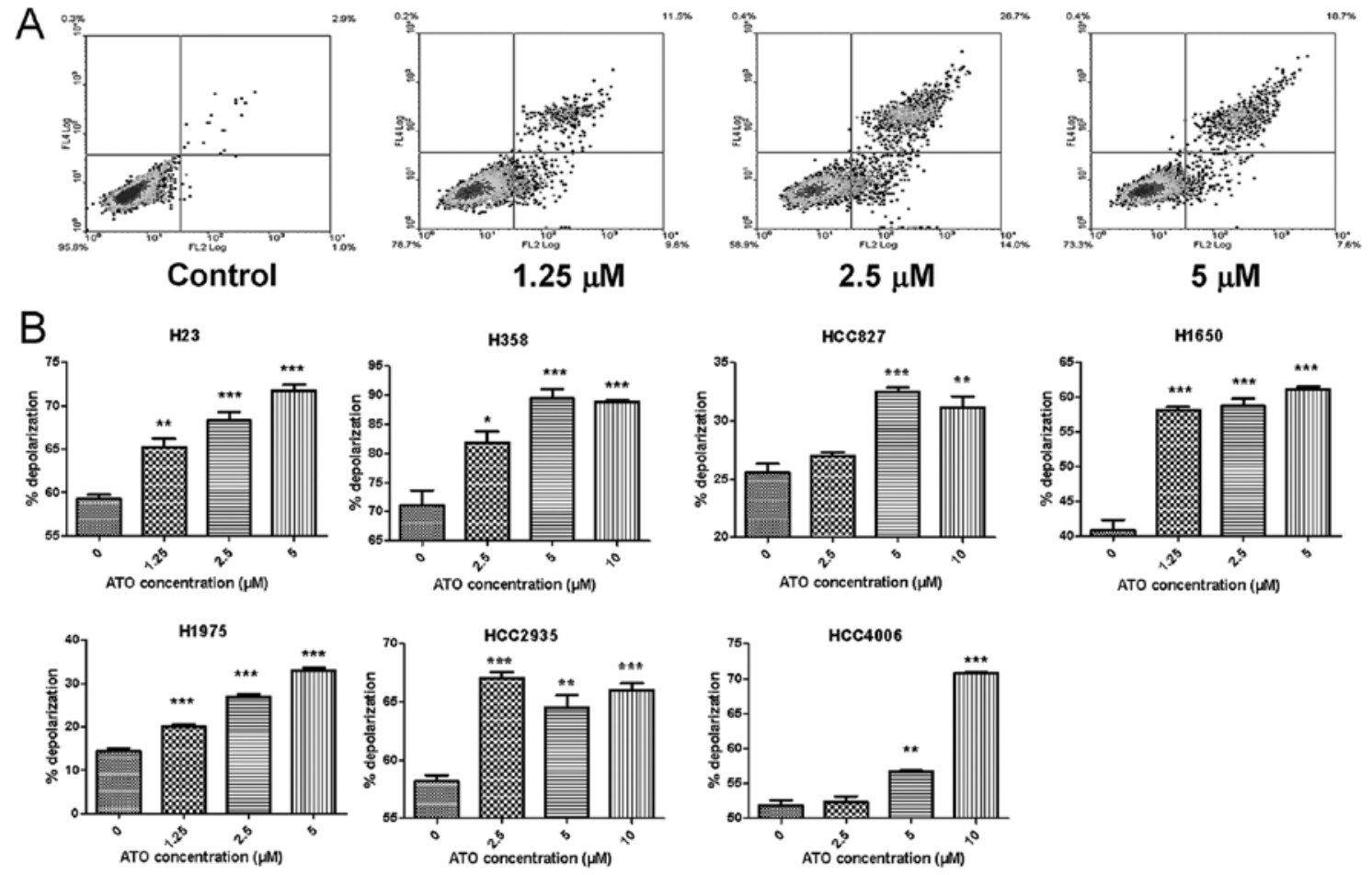

Figure 3. PE-conjugated Annexin V/7-AAD staining and JC-1 staining of ATO-treated lung adenocarcinoma cells. (A) Phosphatidylserine externalization was observed in ATO-treated $\mathrm{H} 23$ cells as evidenced by an increased percentage of cells stained with Annexin V. (B) Cells with depolarized mitochondrial membrane were elevated in all cell lines after incubation with ATO. Statistical significance $\left({ }^{*} \mathrm{p}<0.05,{ }^{* *} \mathrm{p}<0.01,{ }^{* * *} \mathrm{p}<0.001\right)$ is indicated for comparison with control. 

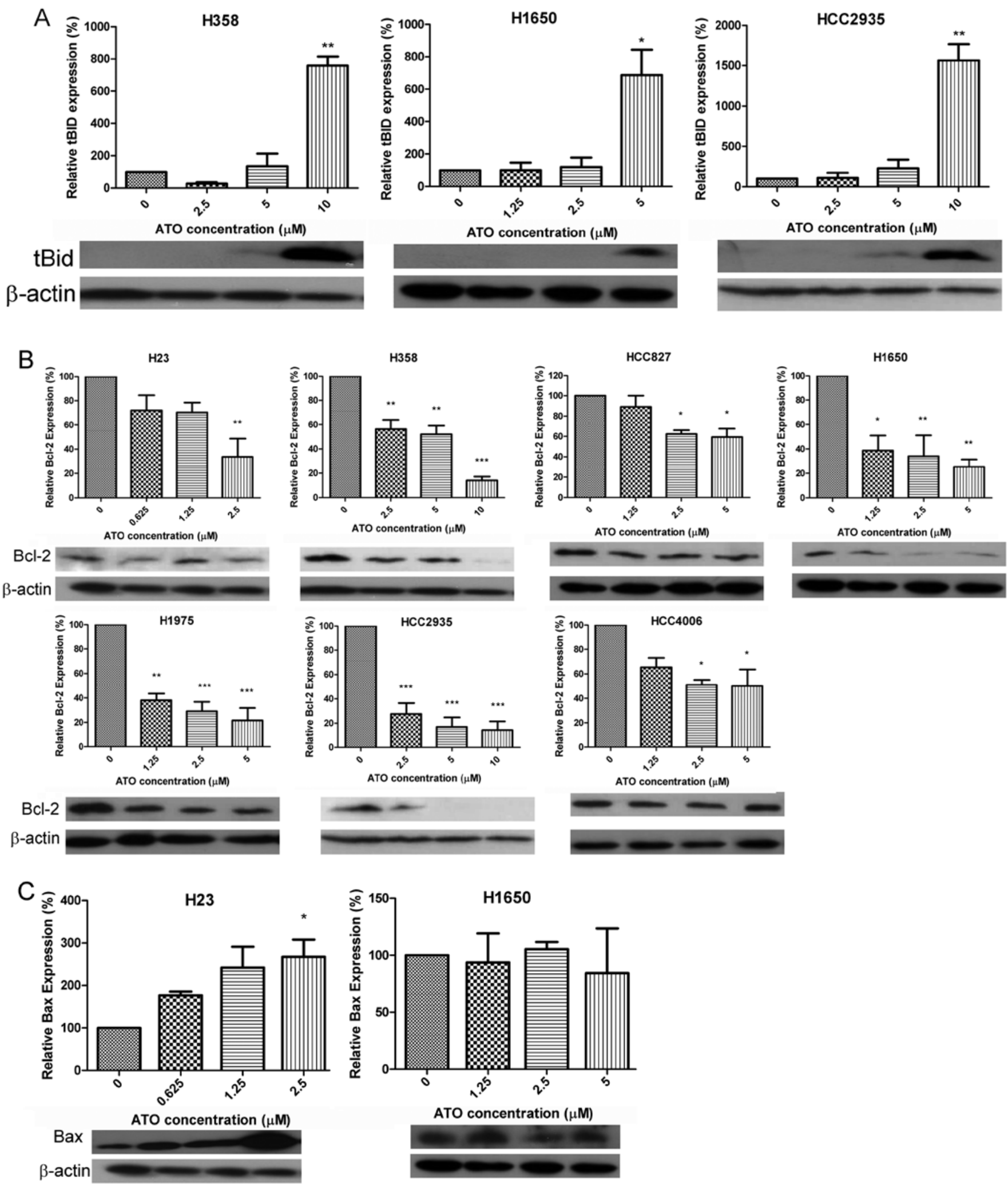

Figure 4. Alteration of apoptotic factors in lung adenocarcinoma cell lines by ATO. Truncation of BID was observed in H358, H1650 and HCC2935 cells (A). Bcl-2 was downregulated in all cell lines (B). Upregulated Bax was found in $\mathrm{H} 23$ cells (C).

were then randomly assigned to two treatment groups with no significant difference in baseline tumor volume. Tumor growth was significantly suppressed in the ATO treatment group compared with controls during 8 days of treatment (Fig. 5A). As the tumor size had reached the humane endpoint (a width of $17 \mathrm{~mm}$ ) in control group, mice were sacrificed after 8 days of treatment. The relative tumor volume in the ATO treatment arm was $32 \%$ that of the control group at the end of treatment $(p=0.0072)$. No obvious toxic effect due to ATO treatment was noted and all the mice were alive following 8 days of treatment. 

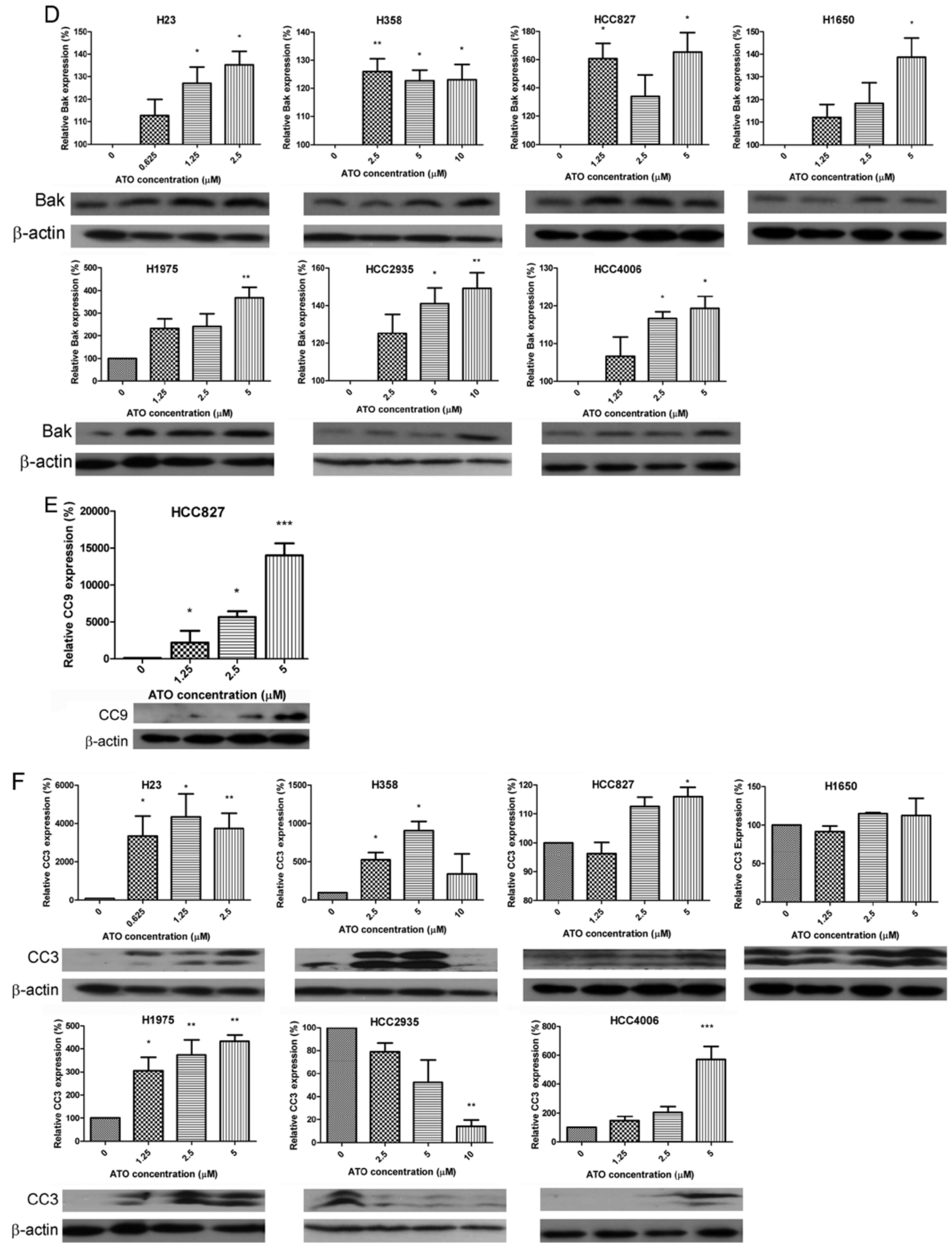

Figure 4. Continued. The expression of Bak was elevated in all cell lines (D). Caspase-9 was activated in HCC827 cells (E). Cleaved caspase-3 (CC3) was upregulated by ATO in H23, H358, HCC 827, H1975 and HCC4006 cells. The expression of CC 3 was unchanged in H1650 cells. CC 3 expression was decreased in $\mathrm{H} 358$ and $\mathrm{HCC} 2935$ cells with $10 \mu \mathrm{M}$ ATO (F). 

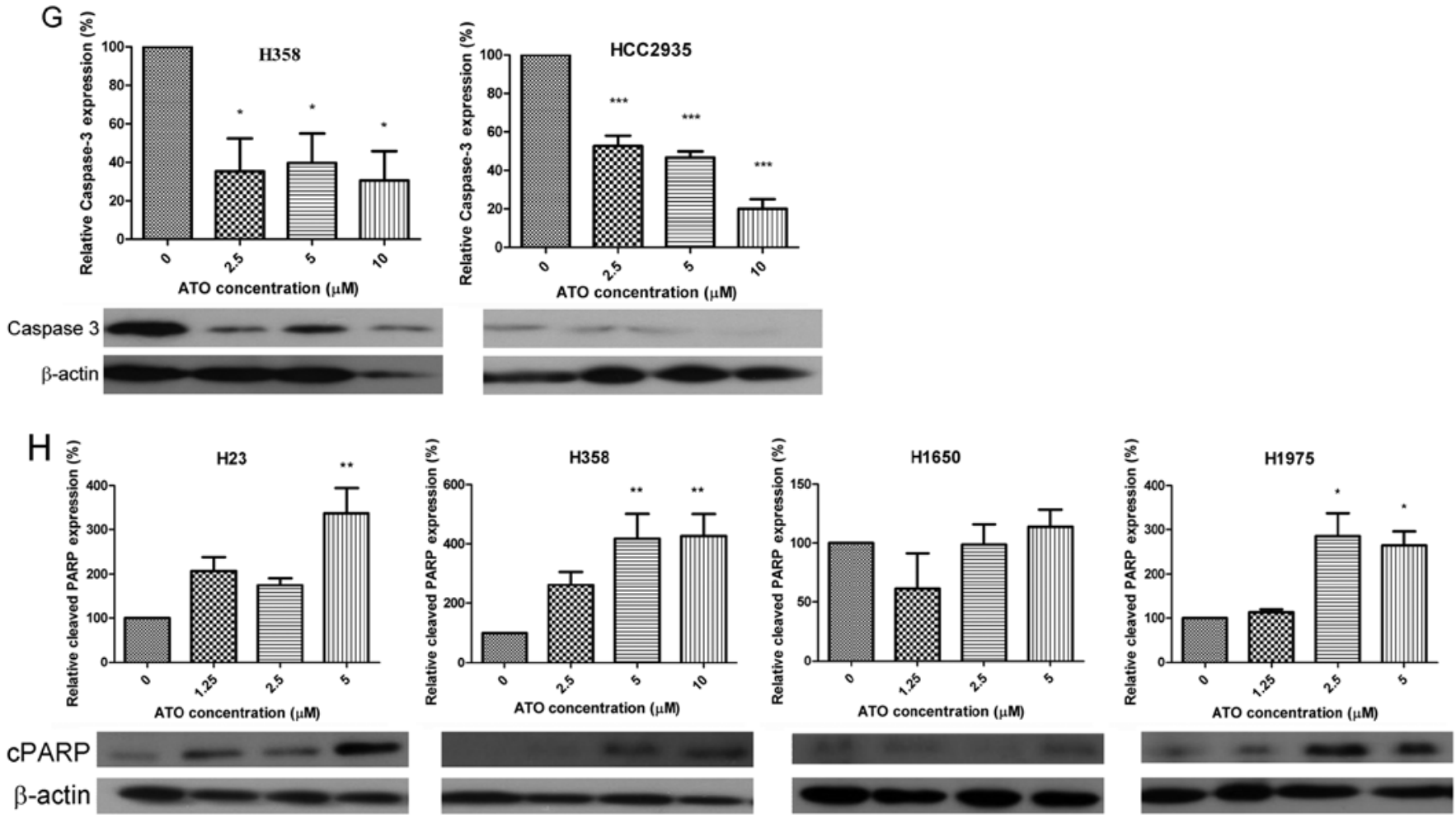

Figure 4. Continued. Caspase-3 was downregulated in H358 and HCC2935 cells (G). Cleavage of PARP was observed in H23, H358 and H1975 cells (H). A representative western blot was shown except for those with undetectable basal expression. $\beta$-actin was used as a housekeeping protein. Statistical significance $\left({ }^{*} \mathrm{p}<0.05,{ }^{* *} \mathrm{p}<0.01,{ }^{* * *} \mathrm{p}<0.001\right)$ is indicated for comparison with control.
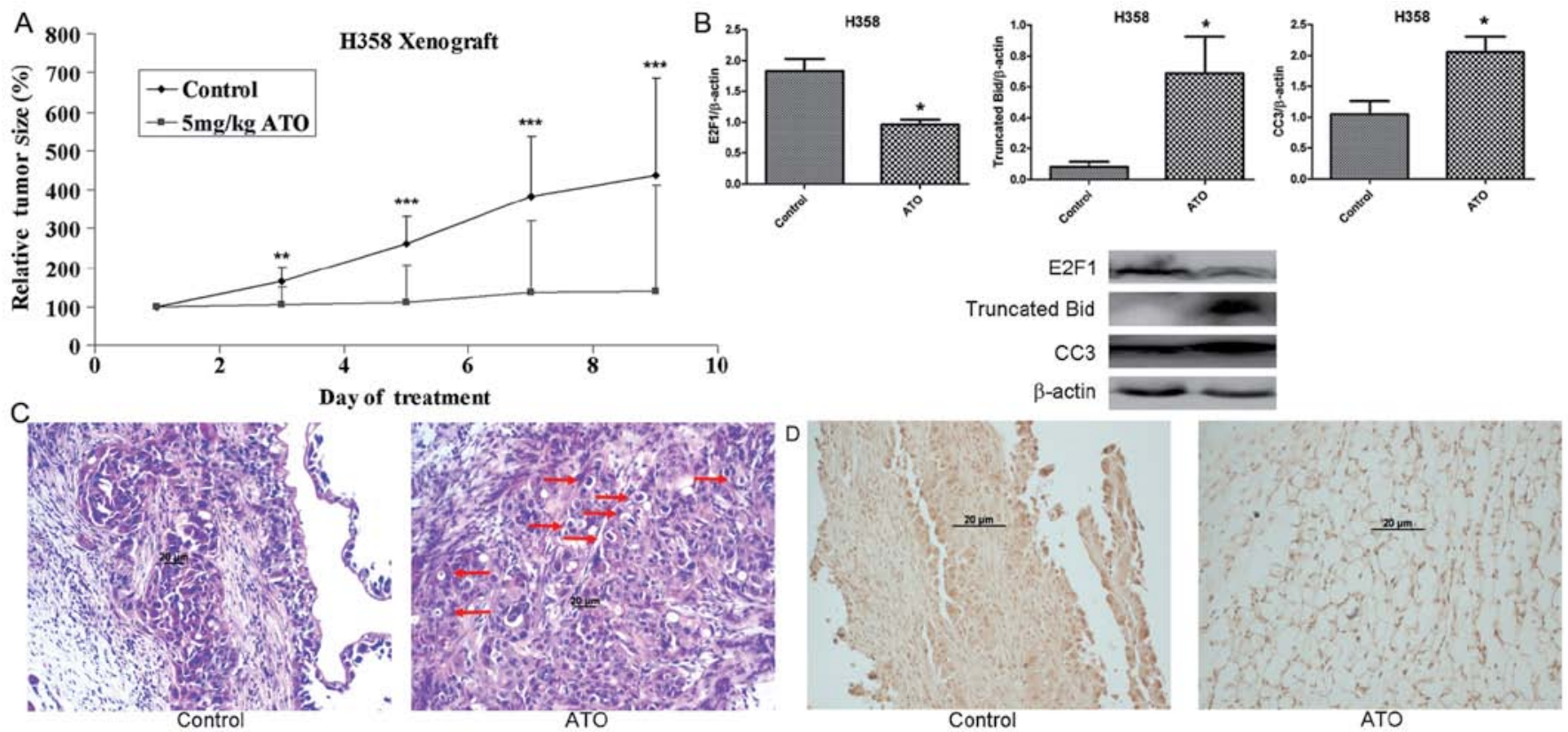

Figure 5. Tumor growth in vivo was inhibited by ATO in H358 xenograft model. ATO treatment was associated with (A) suppression of tumor growth and (B) downregulation of E2F1 as well as upregulation of truncated BID and CC3 expression in the ATO treatment group compared with control group in H358 xenograft model. Statistical significance $\left({ }^{*} \mathrm{p}<0.05,{ }^{* *} \mathrm{p}<0.01,{ }^{* * * *} \mathrm{p}<0.001\right)$ was indicated for comparison with control. (C) Tumor sections were examined histologically with $\mathrm{H} \& \mathrm{E}$ staining, showing prominent apoptosis (examples indicated by arrows) among the ATO treatment group. Representative histological sections of tumor xenografts are shown (x200). (D) Immunostaining for CC3 showed nuclear localization in ATO-treated xenografts, while a lack of compartmentalization was evident in the control.

The body weight of mice in the ATO treatment group and control group was similar during treatment. Based on western blotting, E2F1 protein was downregulated and truncated BID and cleaved caspase-3 were upregulated with ATO treatment (Fig. 5B). Histological examination (H\&E staining) of tumor sections revealed prominent apoptosis (formation of apoptosis 
bodies) with ATO treatment (Fig. 5C). Immunohistochemical staining demonstrated nuclear localization of cleaved caspase-3 in the ATO treatment group (Fig. 5D).

\section{Discussion}

In our cell line and xenograft models, ATO has demonstrated anti-proliferative and cytotoxic activity in lung adenocarcinoma at least partially mediated via downregulation of E2F1 and apoptosis. The concentrations of ATO corresponding to the in vitro $\mathrm{IC}_{50}$ values were within a clinically reachable plasma level $(8.3 \mu \mathrm{M})(17)$. The regulatory role of E2F1 in cellular proliferation in lung adenocarcinoma cell lines was confirmed using E2F1 siRNA knockdown experiment.

$P i$ Shuang is notoriously poisonous and has been paradoxically used in traditional Chinese medicine to treat various conditions, including cancers. The active ingredient of Pi Shuang is now known to be arsenic trioxide $\left(\mathrm{As}_{2} \mathrm{O}_{3}\right.$ or ATO). ATO has been shown to induce apoptosis (at 0.5-2 $\mu \mathrm{M}$ ) and promote cellular differentiation (at $0.1-0.5 \mu \mathrm{M}$ ) in acute promyelocytic leukemia (APL) cells (18). Its mechanisms of action in leukemia have been extensively investigated in the past decade, and involve alteration or activation of Bcl-2, cytochrome $c$, caspase-9, -3 and reactive oxygen species (19), p73, XIAP, cIAP2, Bcl-xL and survivin (20), DNA mutation and apoptosis (21), tubulin assembly disarrangement and microtubule depolymerization (22), survivin and telomerase (7). An intravenous formulation of ATO has received approval from the US Food and Drug Administration in the treatment of APL. In recent years, our institution has developed an oral liquid form of ATO that is more convenient for clinical use with a better safety profile (5). The role of ATO in the treatment of NSCLC has been less well-defined, though some preclinical data have suggested potential activity. We therefore aimed to further investigate the activity and mechanisms of action of ATO in preclinical models of lung adenocarcinoma.

The role of E2F1 in cancer appears to be a double-edged sword, with oncogenic or tumor suppressive properties, depending on the specific cancer type. In human breast cancer: E2F1 mRNA expression was lower with more advanced tumor stage in malignant breast tissue (23), nonetheless E2F1 was shown to promote proliferation in breast cancer cells (24). In NSCLC, E2F1 was reported to be oncogenic (12) and associated with an adverse prognosis (13) that is also observed in thyroid (25), liver (26) and pancreatic (27) cancers.

E2F1 consists of a cyclin A binding domain, DNA binding domain, pocket protein binding domain, nuclear export signal and nuclear localization signal (11). It is a transcription factor that controls apoptosis, cell cycle, senescence and tumor growth (10), as well as DNA damage, repair, synthesis and replication (11). The E2F1 pathway is frequently deregulated in cancers. As a consequence, amplification of cyclin A2 (28), c-myc (29), thymidylate synthase (TYMS) (30) and skp2 (31) is commonly found in various tumors, serving as important cell cycle regulators that are essential for cell proliferation. Thymidine kinase (TK) overexpression is associated with a higher incidence of clinical disease recurrence and mortality in breast cancer (32), while a lower level of expression of ribonucleotide reductase M1 (RRM1) predicts a longer time to progression in lung cancer with chemotherapy treatment
(33). Activation of c-Jun is correlated with CHOP upregulation and induction of apoptosis by AW00178 in human H1299 lung carcinoma cells (34) and apoptosis activation by 6-(7-nitro2,1,3-benzoxadiazol-4-ylthio)hexanol in multidrug-resistant small cell lung cancer H69AR cells (35). These important molecular signals are ultimately controlled by E2F1. In this study, ATO has been shown to suppress E2F1 expression with alteration of its downstream targets. Notably TYMS (9), TK and RRM1 were downregulated, leading to inhibition of DNA synthesis. In addition, decreased expression of other proliferation factors (cyclin A2, c-myc, skp2) may also have contributed to the observed antiproliferative effect of ATO.

While E2F1 has been reported as an oncogene (12), its functional role in lung adenocarcinoma was demonstrated by specific E2F1 siRNA knockdown in our cell line model. Upon E2F1 knockdown by $50-80 \%$, cell viability was significantly reduced by $60-88 \%$, in support of its critical role in cell survival. The same phenomenon was recently reported in other lung cancer cell lines (36), nonetheless neither downstream targets of E2F1 nor other possible mechanisms were studied. In our study, E2F1 and its downstream targets were downregulated with ATO treatment, while the pro-apoptotic factor p-c-Jun was upregulated. As an executioner of apoptosis, expression of cleaved caspase-3 (CC3) after E2F1 knockdown was investigated. By simply knocking down E2F1, expression of CC3 was increased in HCC2935 cells only (data not shown), suggesting that $\mathrm{E} 2 \mathrm{~F} 1$ is mainly responsible for cell proliferation rather than apoptosis.

Although the induction of cell death by ATO has been investigated extensively in different cancer models, only a few reports have shown ATO-induced PS externalization (37-41). To our knowledge, this is the first report of PS externalization in an ATO-treated lung cancer cell line (H23). Nonetheless flow analysis did reveal that more cells became susceptible to mitochondrial membrane depolarization across different cell lines in our model with treatment of increasing ATO concentration, similar to previous reports in both lung cancer $(8,42,43)$ and other cancer cell lines $(44-46)$.

Theoretically, truncation of BID can increase the expression of Bax and Bak. Together with reduction in the expression of Bcl-2, an anti-apoptotic factor, truncated BID can direct the activation of caspase- 9 and -3 . The activation of caspase- 3 may then cleave PARP leading to apoptosis. Thus the key apoptotic factors related to mitochondrial pathway were investigated in our lung adenocarcinoma cell line model with ATO treatment.

The expression of Bcl-2 was frequently inhibited by ATO in other lung cancer cell lines $(8,47,48)$. In accordance with previous reports, we have demonstrated downregulation of Bcl-2 expression in our panel of ATO-treated lung adenocarcinoma cell lines. Upregulation of Bax was induced by ATO in H23 cells, while a similar phenomenon was only reported in small cell lung carcinoma (49). Nonetheless expression of Bak was elevated across different lung adenocarcinoma cell lines with ATO treatment. This is the first report to date of BID truncation and Bak upregulation in ATO-treated lung cancer cell lines.

Although there are reports of cleaved caspase-9 upregulation by ATO in other cancer cell lines $(50,51)$, our similar observation in HCC827 cells is the first report in a lung cancer model. Caspase-3 activation was shown in ATO-treated A549 cells (52), Calu-6 cells (8) and SCLC cell lines (49). This study 
has reinforced these findings in a panel of lung adenocarcinoma cell lines. Interestingly, the expression of CC3 in H358 cells was first increased when exposed to $5 \mu \mathrm{M}$ ATO and then decreased with $10 \mu \mathrm{M}$ ATO, whereas, CC3 expression decreased in a dosedependent manner in HCC2935 cells when incubated with ATO. A similar observation was reported with prolonged incubation of ATO in lymphocytic leukemia cells (53). This paradoxical result was due to the direct suppression of caspase-3 expression by ATO in H358 and HCC2935 cells, and has been previously reported (53). ATO-induced cleavage of PARP has been reported in the H1355 NSCLC cell line (54) and in SCLC cell lines (49). We have provided further evidence of PARP cleavage in lung adenocarcinoma cell lines with ATO treatment.

Apart from promising in vitro activity in our lung adenocarcinoma model, the in vivo effect of ATO was confirmed using a nude mouse xenograft model. E2F1 downregulation was observed in tumor xenografts in keeping with the antiproliferative effect of ATO. Moreover, formation of apoptotic bodies and upregulation of truncated Bid and CC3 were also observed in treated tumor xenografts. Translocation of CC3 from the cytoplasm to the nucleus was shown by IHC staining. Pro-caspase- 3 is located predominantly in the cytoplasm of cells. Caspase- 3 is activated by upstream caspases and its active form (CC3) is then translocated into the nucleus. The substrates in the nucleus, e.g., PARP, are then cleaved. Eventually, chromatin condensation, DNA fragmentation and nuclear disruption occur and cells are directed to apoptosis (55). Our findings have provided evidence that apoptosis is induced by ATO in a lung adenocarcinoma xenograft model.

In conclusion, the anticancer effect of ATO was demonstrated through antiproliferation (E2F1 downregulation) and cell death (apoptosis) in both in vitro and in vivo lung adenocarcinoma models. Our novel finding of E2F1 suppression by ATO provides an additional mechanism to explain the activity of ATO in lung adenocarcinoma. Future potential clinical applications of ATO in lung adenocarcinoma treatment should be explored.

\section{Acknowledgements}

This study was supported by the Simon K.Y. Lee Foundation research fund and the University of Hong Kong small project funding.

\section{References}

1. Yano T, Haro A, Shikada Y, Maruyama R and Maehara Y: Non-small cell lung cancer in never smokers as a representative 'non-smoking-associated lung cancer': epidemiology and clinical features. Int J Clin Oncol 16: 287-293, 2011.

2. Favaretto AG, Pasello G and Magro C: Second and third line treatment in advanced non-small cell lung cancer. Discov Med 8: 204-209, 2009.

3. Goldstraw P, Crowley J, Chansky K, et al: The IASLC Lung Cancer Staging Project: proposals for the revision of the TNM stage groupings in the forthcoming (seventh) edition of the TNM classification of malignant tumours. J Thorac Oncol 2: 706-714, 2007.

4. Suda K, Onozato R, Yatabe Y and Mitsudomi T: EGFR T790M mutation: a double role in lung cancer cell survival? J Thorac Oncol 4: 1-4, 2009.

5. Au WY, Kumana CR, Kou M, et al: Oral arsenic trioxide in the treatment of relapsed acute promyelocytic leukemia. Blood 102: 407-408, 2003.
6. Chien CW, Yao JH, Chang SY, Lee PC and Lee TC: Enhanced suppression of tumor growth by concomitant treatment of human lung cancer cells with suberoylanilide hydroxamic acid and arsenic trioxide. Toxicol Appl Pharmacol 257: 59-66, 2011.

7. Ghaffari SH, Momeny M, Bashash D, Mirzaei R, Ghavamzadeh A and Alimoghaddam K: Cytotoxic effect of arsenic trioxide on acute promyelocytic leukemia cells through suppression of NFkbeta-dependent induction of hTERT due to down-regulation of Pin1 transcription. Hematology 17: 198-206, 2012.

8. Han YH, Kim SZ, Kim SH and Park WH: Arsenic trioxide inhibits the growth of Calu- 6 cells via inducing a G2 arrest of the cell cycle and apoptosis accompanied with the depletion of GSH. Cancer Lett 270: 40-55, 2008.

9. Lam SK, Mak JC, Zheng CY, Li YY, Kwong YL and Ho JC: Downregulation of thymidylate synthase with arsenic trioxide in lung adenocarcinoma. Int J Oncol 44: 2093-2102, 2014.

10. Slee EA and $\mathrm{Lu} \mathrm{X}$ : Requirement for phosphorylation of P53 at Ser312 in suppression of chemical carcinogenesis. Sci Rep 3: $3105,2013$.

11. Tsantoulis PK and Gorgoulis VG: Involvement of E2F transcription factor family in cancer. Eur J Cancer 41: 2403-2414, 2005.

12. Huang CL, Liu D, Nakano J, et al: E2F1 overexpression correlates with thymidylate synthase and survivin gene expressions and tumor proliferation in non small-cell lung cancer. Clin Cancer Res 13: 6938-6946, 2007.

13. Gorgoulis VG, Zacharatos P, Mariatos G, et al: Transcription factor E2F-1 acts as a growth-promoting factor and is associated with adverse prognosis in non-small cell lung carcinomas. J Pathol 198: 142-156, 2002.

14. Liontos M, Niforou K, Velimezi G, et al: Modulation of the E2F1driven cancer cell fate by the DNA damage response machinery and potential novel E2F1 targets in osteosarcomas. Am J Pathol 175: 376-391, 2009.

15. Li YY, Lam SK, Mak JC, Zheng CY and Ho JC: Erlotinibinduced autophagy in epidermal growth factor receptor mutated non-small cell lung cancer. Lung Cancer 81: 354-361, 2013.

16. Kousparou CA, Yiacoumi E, Deonarain MP and Epenetos AA: Generation of a selectively cytotoxic fusion protein against p53 mutated cancers. BMC Cancer 12: 338, 2012.

17. Yamauchi K IY, Ogata K, Hara S, Tamura K, Suzumiya J, Ishitsuka K and Ono N: Pharmacokinetics of arsenic trioxide in Japanese patients with acute promyelocytic leukemia and adult T-cell leukemia lymphoma. Jpn J Pharmaceut Health Care Sci 30: 492-496, 2004.

18. Chen GQ, Shi XG, Tang W, et al: Use of arsenic trioxide $\left(\mathrm{As}_{2} \mathrm{O}_{3}\right)$ in the treatment of acute promyelocytic leukemia (APL): I. $\mathrm{As}_{2} \mathrm{O}_{3}$ exerts dose-dependent dual effects on APL cells. Blood 89: 3345-3353, 1997.

19. Bustamante J, Nutt L, Orrenius S and Gogvadze V: Arsenic stimulates release of cytochrome $c$ from isolated mitochondria via induction of mitochondrial permeability transition. Toxicol Appl Pharmacol 207: 110-116, 2005.

20. Momeny M, Zakidizaji M, Ghasemi R, et al: Arsenic trioxide induces apoptosis in NB-4, an acute promyelocytic leukemia cell line, through up-regulation of p73 via suppression of nuclear factor kappa B-mediated inhibition of p73 transcription and prevention of NF-kappaB-mediated induction of XIAP, cIAP2, BCL-XL and survivin. Med Oncol 27: 833-842, 2010.

21. Meng R, Zhou J, Sui M, Li Z, Feng G and Yang B: Arsenic trioxide promotes mitochondrial DNA mutation and cell apoptosis in primary APL cells and NB4 cell line. Sci China Life Sci 53: 87-93, 2010.

22. Baek JH, Moon CH, Cha SJ, et al: Arsenic trioxide induces depolymerization of microtubules in an acute promyelocytic leukemia cell line. Korean J Hematol 47: 105-112, 2012.

23. Worku D, Jouhra F, Jiang GW, Patani N, Newbold RF and Mokbel K: Evidence of a tumour suppressive function of E2F1 gene in human breast cancer. Anticancer Res 28: 2135-2139, 2008.

24. Xu F, You X, Liu F, et al: The oncoprotein HBXIP up-regulates Skp2 via activating transcription factor E2F1 to promote proliferation of breast cancer cells. Cancer Lett 333: 124-132, 2013.

25. Onda M, Nagai H, Yoshida A, et al: Up-regulation of transcriptional factor E2F1 in papillary and anaplastic thyroid cancers. J Hum Genet 49: 312-318, 2004.

26. Farra R, Dapas B, Pozzato G, et al: Effects of E2F1-cyclin E1-E2 circuit down regulation in hepatocellular carcinoma cells. Dig Liver Dis 43: 1006-1014, 2011. 
27. Yamazaki K, Yajima T, Nagao T, et al: Expression of transcription factor E2F-1 in pancreatic ductal carcinoma: an immunohistochemical study. Pathol Res Pract 199: 23-28, 2003.

28. Yam CH, Fung TK and Poon RY: Cyclin A in cell cycle control and cancer. Cell Mol Life Sci 59: 1317-1326, 2002.

29. Hilbe W, Dirnhofer S, Greil R and Woll E: Biomarkers in non-small cell lung cancer prevention. Eur J Cancer Prev 13: 425-436, 2004.

30. Ceppi P, Rapa I, Lo Iacono M, et al: Expression and pharmacological inhibition of thymidylate synthase and Src kinase in nonsmall cell lung cancer. Int J Cancer 130: 1777-1786, 2012.

31. Hung WC, Tseng WL, Shiea J and Chang HC: Skp2 overexpression increases the expression of MMP-2 and MMP-9 and invasion of lung cancer cells. Cancer Lett 288: 156-161, 2010.

32. Huang ZH, Tian XS, Li R, et al: Elevated thymidine kinase 1 in serum following neoadjuvant chemotherapy predicts poor outcome for patients with locally advanced breast cancer. Exp Ther Med 3: 331-335, 2012.

33. Wang L, Meng L, Wang XW, Ma GY and Chen JH: Expression of RRM1 and RRM2 as a novel prognostic marker in advanced non-small cell lung cancer receiving chemotherapy. Tumour Biol 35: 1899-1906, 2014.

34. Ryu BJ, Hwang MK, Park M, Lee K and Kim SH: Thiourea compound AW00178 sensitizes human H1299 lung carcinoma cells to TRAIL-mediated apoptosis. Bioorg Med Chem Lett 22: 3862-3865, 2012.

35. Filomeni G, Turella P, Dupuis ML, et al: 6-(7-Nitro-2,1,3benzoxadiazol-4-ylthio)hexanol, a specific glutathione S-transferase inhibitor, overcomes the multidrug resistance (MDR)-associated protein 1-mediated MDR in small cell lung cancer. Mol Cancer Ther 7: 371-379, 2008

36. Walker T, Nolte A, Steger V, et al: Small interfering RNA-mediated suppression of serum response factor, E2-promotor binding factor and survivin in non-small cell lung cancer cell lines by non-viral transfection. Eur J Cardiothorac Surg 43: 624-633, 2013.

37. Hu T, Shi J, Jiao X, Zhou J and Yin X: Measurement of Annexin $\mathrm{V}$ uptake and lactadherin labeling for the quantification of apoptosis in adherent Tca8113 and ACC-2 cells. Braz J Med Biol Res 41: 750-757, 2008.

38. Korper S, Nolte F, Thiel E, Schrezenmeier H and Rojewski MT: The role of mitochondrial targeting in arsenic trioxide-induced apoptosis in myeloid cell lines. Br J Haematol 124: 186-189, 2004

39. Shen ZY, Shen J, Cai WJ, Hong C and Zheng MH: The alteration of mitochondria is an early event of arsenic trioxide induced apoptosis in esophageal carcinoma cells. Int J Mol Med 5: $155-158,2000$

40. Wang $\mathrm{Y}, \mathrm{Xu} \mathrm{Y}$, Wang $\mathrm{H}$, et al: Arsenic induces mitochondriadependent apoptosis by reactive oxygen species generation rather than glutathione depletion in Chang human hepatocytes. Arch Toxicol 83: 899-908, 2009.

41. Xu Y, Wang H, Wang Y, Zheng Y and Sun G: Effects of folate on arsenic toxicity in Chang human hepatocytes: involvement of folate antioxidant properties. Toxicol Lett 195: 44-50, 2010.
42. Jin HO, Seo SK, Woo SH, et al: A combination of sulindac and arsenic trioxide synergistically induces apoptosis in human lung cancer H1299 cells via c-Jun NH2-terminal kinase-dependent Bcl-xL phosphorylation. Lung Cancer 61: 317-327, 2008.

43. Jin HO, Yoon SI, Seo SK, et al: Synergistic induction of apoptosis by sulindac and arsenic trioxide in human lung cancer A549 cells via reactive oxygen species-dependent down-regulation of survivin. Biochem Pharmacol 72: 1228-1236, 2006.

44. Qin DB, Chen JP and Wang SQ: Mechanism of apoptosis of NB4 cells induced by arsenic trioxide and cyclooxygenase- 2 expression. Zhongguo Shi Yan Xue Ye Xue Za Zhi 19: 648-651, 2011 (In Chinese).

45. Su Y, Wang X, Xu W, et al: Arsenic trioxide increases the sensitivity of 786-0 renal carcinoma cells to radiotherapy. Cancer Invest 30: 114-118, 2012.

46. Tung JN, Cheng YW, Hsu CH, et al: Normoxically overexpressed hypoxia inducible factor 1-alpha is involved in arsenic trioxide resistance acquisition in hepatocellular carcinoma. Ann Surg Oncol 18: 1492-1500, 2011.

47. Li HC, Wang CX, Huang C, et al: Effect and mechanism of arsenic trioxide on chemosensitivity of human lung adenocarcinoma cells. Zhonghua Jie He He Hu Xi Za Zhi 26: 689-692, 2003 (In Chinese)

48. Shi Y, Liu Y, Huo J and Gao G: Arsenic trioxide induced apoptosis and expression of p53 and bcl-2 genes in human small cell lung cancer cells. Zhonghua Jie He He Hu Xi Za Zhi 25: 665-666, 2002

49. Pettersson HM, Pietras A, Munksgaard Persson M, et al: Arsenic trioxide is highly cytotoxic to small cell lung carcinoma cells. Mol Cancer Ther 8: 160-170, 2009.

50. Yuan Z, Wang F, Zhao Z, et al: BIM-mediated AKT phosphorylation is a key modulator of arsenic trioxide-induced apoptosis in cisplatin-sensitive and -resistant ovarian cancer cells. PLoS One 6: e20586, 2011.

51. Potin S, Bertoglio J and Breard J: Involvement of a RhoROCK-JNK pathway in arsenic trioxide-induced apoptosis in chronic myelogenous leukemia cells. FEBS Lett 581: 118-124, 2007.

52. Walker AM, Stevens JJ, Ndebele K and Tchounwou PB: Arsenic trioxide modulates DNA synthesis and apoptosis in lung carcinoma cells. Int J Environ Res Public Health 7: 1996-2007, 2010.

53. Bairey O, Vanichkin A and Shpilberg O: Arsenic-trioxideinduced apoptosis of chronic lymphocytic leukemia cells. Int J Lab Hematol 32: e77-85, 2010.

54. Cheng Y, Chang LW and Tsou TC: Mitogen-activated protein kinases mediate arsenic-induced down-regulation of survivin in human lung adenocarcinoma cells. Arch Toxicol 80: 310-318, 2006.

55. Luo M, Lu Z, Sun H, et al: Nuclear entry of active caspase- 3 is facilitated by its $\mathrm{p3}$-recognition-based specific cleavage activity. Cell Res 20: 211-222, 2010. 